\title{
Ancient mitochondrial DNA sequences of Jomon teeth samples from Sanganji, Tohoku district, Japan
}

\author{
Hideaki KANZAWA-KIRIYAMA ${ }^{1,2}$, Aiko SASO ${ }^{3,4}$, Gen SuWA ${ }^{4}$, Naruya SAITOU ${ }^{2,1,3 *}$ \\ ${ }^{1}$ Department of Genetics, School of Life Science, Graduate University for Advanced Studies, Mishima 411-8540, Japan \\ ${ }^{2}$ Division of Population Genetics, National Institute of Genetics, Mishima 411-8540, Japan \\ ${ }^{3}$ Department of Biological Sciences, The University of Tokyo, Tokyo 113-0033, Japan \\ ${ }^{4}$ The University Museum, The University of Tokyo, Tokyo 113-0033, Japan
}

Received 18 May 2012; accepted 13 November 2012

\begin{abstract}
We investigated mitochondrial DNA haplogroups of four Jomon individuals from the Sanganji shell mound in Fukushima, Tohoku district, Japan. Partial nucleotide sequences of the coding and control region of mitochondrial DNA were determined. The success rate of sequencing increased when we analyzed short DNA sequences. We identified haplogroups from all four samples that were analyzed; haplogroup frequencies were $50 \%(n=2)$ for $\mathrm{N} 9 \mathrm{~b}$ and $50 \%(n=2)$ for M7a2. Haplogroup $\mathrm{N} 9 \mathrm{~b}$ has been previously observed in high frequencies in the other Tohoku Jomon, Hokkaido Jomon, Okhotsk, and Ainu peoples, whereas its frequency was reported to be low in the Kanto Jomon and the modern mainland Japanese. Sub-haplogroup M7a2 has previously been reported in the Hokkaido Jomon, Okhotsk, and modern Udegey (southern Siberia) peoples, but not in the Kanto Jomon, Ainu, or Ryukyuan peoples. Principal component analysis and phylogenetic network analysis revealed that, based on haplogroup frequencies, the Tohoku Jomon was genetically closer to the Hokkaido Jomon and Udegey people, than to the Kanto Jomon or mainland modern Japanese. The available evidence suggests genetic differences between the Tohoku and Kanto regions in the Jomon period, and greater genetic similarity between the Tohoku Jomon and the other investigated ancient (Hokkaido Jomon, Okhotsk) and modern (Siberian, Udegey in particular) populations. At the same time, the Tohoku and Hokkaido Jomon seem to differ in sub-haplotype representations, suggesting complexity in Jomon population structure and history.
\end{abstract}

Key words: Mitochondrial DNA, ancient DNA, Sanganji shell mound, Jomon, Tohoku region

\section{Introduction}

The question of the origin of the Jomon people has been debated for several decades. The Jomon are widely thought to have settled the Japanese archipelago c. 15700 to 2350 years BP (Kobayashi, 2008) and ranged geographically from Hokkaido to Okinawa. Morphological studies of dental variation have suggested that the Jomon people were of southern origin (Turner, 1987, 1990; Hanihara, 1991; Matsumura, 2007; Matsumura et al., 2009). On the other hand, archaeology, genetics, and recent cranial morphology studies suggest that the Jomon people were of northern origin (Nei, 1995; Imamura, 1996; Omoto and Saitou, 1997; Hanihara and Ishida, 2009; Nakashima et al., 2010).

To investigate more directly the origin of the Jomon from a genetic standpoint, mitochondrial (mt) DNA from ancient skeletal remains have been analyzed in the last few decades (Horai et al., 1989, 1991; Shinoda and Kanai, 1999; Shinoda,

* Correspondence to: Naruya Saitou, Division of Population Genetics, National Institute of Genetics, 1111 Yata, Mishima 411-8540, Japan.

E-mail: saitounr@nig.ac.jp

Published online 7 March 2013

in J-STAGE (www.jstage.jst.go.jp) DOI: 10.1537/ase.121113
2003; Adachi et al., 2008, 2009a, b, 2011). Analyses of ancient materials are useful, because they directly clarify maternally inherited mtDNA haplogroups. So far, Jomon materials from three regions, the Hokkaido, Tohoku, and Kanto regions (Figure 1), have been analyzed (Shinoda and Kanai, 1999; Shinoda, 2003; Adachi et al., 2008, 2009a, b, 2011). Comparisons of mtDNA haplogroup frequencies with other East and Northeast Asian populations indicate that the genetic structure of the Hokkaido Jomon (the northernmost of the Jomon populations) exhibited some similarities with indigenous modern Siberian populations inhabiting the lower Amur riverine system, particularly the Ulchi and Udegey people (Adachi et al., 2011). However, the genetic affinity of the other Jomon people, especially of the Tohoku Jomon, was not sufficiently classified in Adachi et al. (2009a). Furthermore, the mtDNA haplogroups N9b and M7a, characteristic of the Tohoku Jomon, are scarce in the other modern populations except the modern Japanese (including Ainu and Ryukyuan people) and Udegey. In order to further understand the origin of the Jomon people based on ancient DNA, additional analyses of the Tohoku Jomon are essential.

In this study, we analyzed samples taken from skeletal remains of the late to final Jomon period Sanganji shell mound site of Fukushima Prefecture, Tohoku district, Japan. 


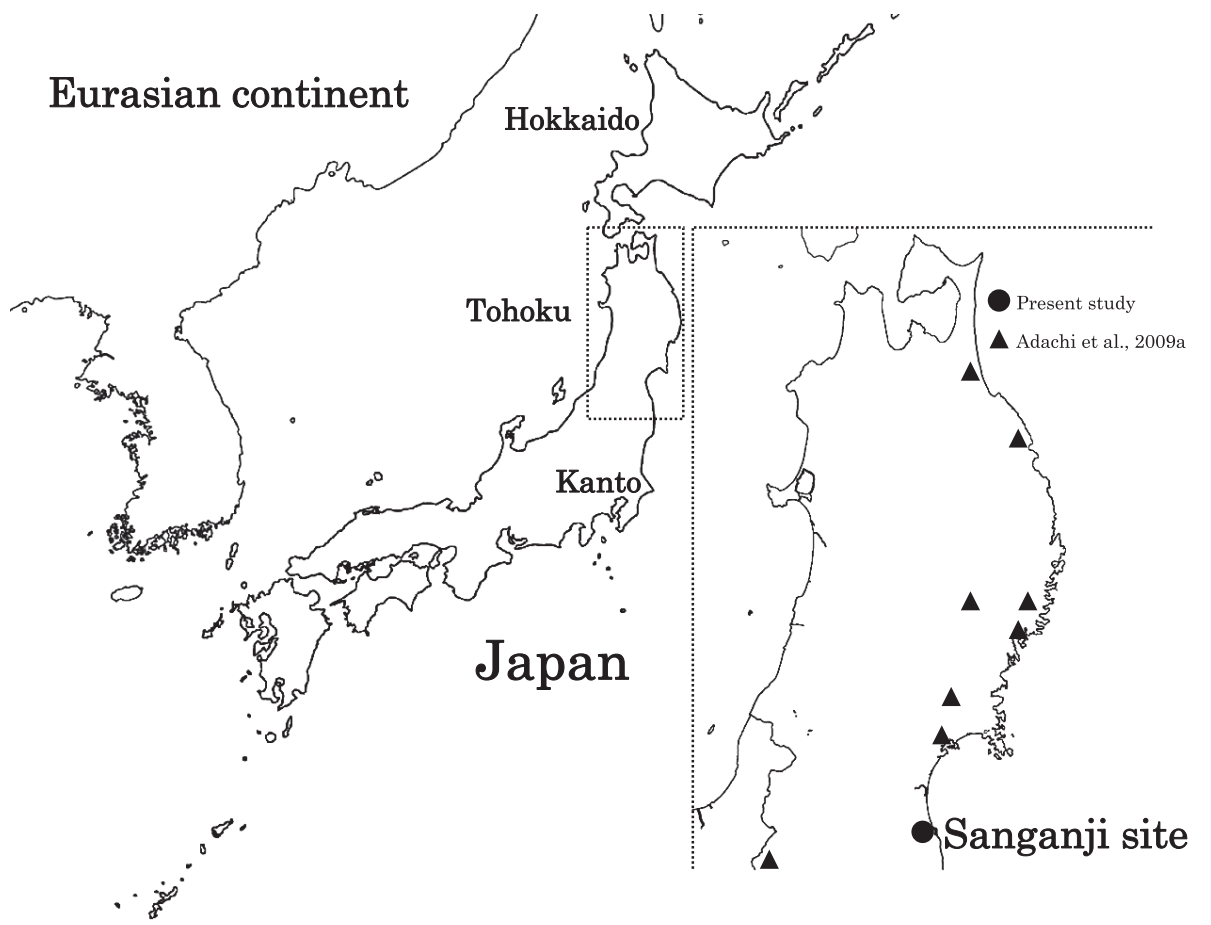

Figure 1. Geographical location of Sanganji site, and other sites of Tohoku Jomon people.

The remains that we examined are part of the skeletal collection excavated in 1952 and 1954, and have been stored in The University Museum, The University of Tokyo for more than 50 years. It is known that excessive handling and longterm storage may influence the ability to obtain authentic endogenic DNA (Melchior et al., 2010). Because the success rates of ancient DNA studies increase when shorter DNA regions are analyzed (Pääbo et al., 2004; Haak et al., 2010), we focused on determining nucleotide sequences of the shorter mtDNA regions. As a result, in our sample of four, we were able to determine haplogroups with a $100 \%$ success rate. Our new results from the Sanganji Jomon materials, added to previous data (Adachi et al., 2009a), allow for more detailed population comparisons.

\section{Materials and Methods}

\section{Sample collection}

The Sanganji shell mound is located in the northern part of Fukushima Prefecture, Tohoku district (Figure 1). The chronological age of the burials, belonging to the late to final Jomon period, is considered to lie within the range from 4000 to 2500 years BP. The 1952-1954 excavations of the Sanganji Jomon skeletal remains were carried out by the Special Committee for Jomon Chronology of the Japanese Archaeological Association (1952 excavation), and by the Department of Anthropology, The University of Tokyo (1954 excavation). To analyze mtDNA haplogroups, we used teeth from four Sanganji Jomon individuals housed in The University Museum, The University of Tokyo (Table 1). Three of these came from skeletal remains catalogued as UMUT-131421 (Endo and Endo, 1979), which
Table 1. Information of analyzed Sanganji Jomon teeth samples

\begin{tabular}{llccl}
\hline Sample ID & Sex & $\begin{array}{c}\text { Tooth } \\
\text { ablation type }\end{array}$ & $\begin{array}{c}\text { Date of } \\
\text { excavation }\end{array}$ & $\begin{array}{c}\text { Analyzed } \\
\text { tooth part }\end{array}$ \\
\hline $131421-1$ & Female? & $0^{\mathrm{a}}$ & 1954 & Right M3 \\
$131421-2$ & Male & $0^{\mathrm{a}}$ & 1954 & Right M3 \\
$131421-3$ & Male & $?^{\mathrm{b}}$ & 1954 & Right M2 \\
131464 & Female & $2^{\mathrm{c}}$ & 1952 & Right M2 \\
\hline
\end{tabular}

${ }^{a}$ There are no tooth extractions in the mandibular anterior teeth (all alveoli present), inferring ablation of only the upper canines (or a rare case at Sanganji of no ablation).

${ }^{\mathrm{b}}$ The left $\mathrm{I} 1$ alveolus is closed after tooth loss, while the left $\mathrm{I} 2$ is intact. The right side mandible is not preserved. This suggests either individual tooth ablation interpreted as mourning ablation (Harunari, 2002), a rare case at Sanganji of transitional stage of the 4I pattern (all four lower incisors extracted), or type 0 with natural loss of the left I1.

c All lower anterior teeth (canine and incisors) were extracted, implying the 2C ablation type (all lower anterior teeth and upper canines).

includes six to eight individuals from what is known as secondary burial C' (Fukushima Museum, 1988). In the following analysis, we distinguish these three individuals by suffixes, 131421-1, 131421-2, and 131421-3. The fourth individual that we examined, UMUT-131464 (Endo and Endo, 1979), comes from secondary burial B, which includes approximately 10 individuals (Fukushima Museum, 1988). A single, well-preserved molar tooth was removed from the mandible of each individual (isolated teeth were excluded to avoid the possibility of sampling from the same individual). We chose mandibles which had both right- and left-side molars, so that the antimere of the analyzed tooth would remain available for general morphological studies. 
The ablation patterns of the Jomon people have been discussed in relation to population movement (Harunari, 2002; Funahashi, 2010). The tooth ablation type of individuals 131421-1 and 131421-2 (no mandibular teeth extracted) was probably 0-type (only the upper canine extracted, no mandibular tooth extraction). According to Harunari's (2002) interpretations, this would indicate in-group status of the individuals and not immigration through marriage. If so, these two individuals may have been born at Sanganji, and it is possible that they were relatives.

\section{DNA extraction}

Tooth samples were soaked in a 13\% sodium hypochlorite solution for 3 minutes, rinsed several times with HPLCgrade water (Wako, Japan), then treated with ultraviolet radiation at least overnight, and allowed to air-dry under ultraviolet radiation for 60 minutes. The outer surface of the samples was then removed using a heat-treated drill. Next, the samples were again rinsed with HPLC-grade water and allowed to air-dry under ultraviolet radiation for 60 minutes. The tip of the tooth root was cut horizontally using a cutting disk; the dental pulp was reduced to powder with a drill and collected in a tube. DNA extraction from the powdered samples was carried out based on the method of Rohland and Hofreiter (2007) with some modifications. The powdered samples were dissolved with 0.5 M EDTA (pH 8.0) (Wako, Japan) and $0.25 \mathrm{mg} / \mathrm{ml}$ proteinase $\mathrm{K}$ (TaKaRa, Japan) overnight at room temperature. The dissolved solution was centrifuged, and the supernatant was collected. The collected solution was concentrated using VivaSpin6 (Sartorius, Japan) to a volume less than $300 \mu \mathrm{l}$. The concentrated solution was added to $1.5 \mathrm{ml}$ binding buffer ( $5 \mathrm{M} \mathrm{GuSCN}$, $25 \mathrm{mM} \mathrm{NaCl}$, and $50 \mathrm{mM}$ Tris, $\mathrm{pH}$ 8.0) plus $100 \mu \mathrm{l}$ silica suspension (Sigma) and incubated under agitation for 3 hours at room temperature. The silica pellet was collected via centrifugation, the supernatant was removed, and the pellet was washed twice with binding buffer. Subsequently, the pellet was dried at room temperature for 15 minutes. DNA was eluted with $50 \mu \mathrm{l} 1 \times$ TE buffer at room temperature for 10 minutes, and, after centrifugation, the aqueous solution was transferred to a new tube. DNA was eluted twice, and $100 \mu \mathrm{l}$ of DNA extract was finally obtained from each sample.

\section{PCR amplification and sequencing}

Ancient DNA is invariably of shorter length, and the length of the DNA sequences that can be amplified by polymerase chain reaction (PCR) is limited (Pääbo et al., 2004; Haak et al., 2010). Moreover, as heavy handling and prolonged storage influence the ability to obtain authentic endogenic DNA (Melchior et al., 2010), we anticipated that the analysis of Sanganji Jomon samples, excavated in 1952 and 1954, would be difficult and the success rate would be low. To overcome this problem, in addition to the primers that target long DNA segments (158-195 bp), we used short lengths of target DNA (58-90 bp) containing haplogroupspecific SNPs, because shorter DNA regions are more readily amplified by PCR than longer DNA regions (Pääbo et al., 2004; Haak et al., 2010).

To determine mtDNA haplogroups, hypervariable region
Table 2. Primers used for PCR amplifications of mitochondrial DNA hypervariable regions 1 and 2

\begin{tabular}{|c|c|c|c|}
\hline \multicolumn{2}{|r|}{ Primer } & \multirow{2}{*}{$\begin{array}{l}\text { Nucleotide } \\
\text { positions }^{\mathrm{b}}\end{array}$} & \multirow{2}{*}{$\begin{array}{l}\text { Product } \\
\text { size }\end{array}$} \\
\hline ID & Sequence $^{\mathrm{a}}$ & & \\
\hline L127 & AGCACCCTATGTCGCAGTAT & $128-256$ & 169 \\
\hline $\mathrm{H} 257$ & TCTGTGTGGAAAGCGGCTGT & & \\
\hline L15998 & CCATTAGCACCCAAAGCTA & 15999-16141 & 182 \\
\hline H16142 & ATGTACTACAGGTGGTCAAG & & \\
\hline L16120 & TTACTGCCAGCCACCATGAA & $16121-16238$ & 158 \\
\hline H16239 & TGGCTTTGGAGTTGCAGTTG & & \\
\hline L16208 & CCCCATGCTTACAAGCAAG & $16209-16366$ & 195 \\
\hline H16367 & CTGAGGGGGGTCATCCAT & & \\
\hline
\end{tabular}

${ }^{a}$ Primers of Adachi et al. (2009b) were referred.

${ }^{\mathrm{b}}$ Numbers of nucleotide positions are relative to the revised Cambridge Reference Sequence (rCRS) (Andrews et al., 1999).

(HVR)-1, HVR-2, 28 haplogroup/sub-haplogroup-specific single nucleotide polymorphisms (SNPs), and a 9 bp repeat variation in the noncoding cytochrome oxidase II/tRNA ${ }^{\text {Lys }}$ intergenic region, were analyzed following previous publications (Umetsu et al., 2005; van Oven and Kayser, 2008; Adachi et al., 2009a, b, 2011; Haak et al., 2010). The primers used to amplify HVR-1, HVR-2, and haplogroupdetermining regions are listed in Table 2 and Table 3 . Analyzed haplogroups were compared with those of modern Japanese and Jomon people (Horai et al., 1996; Shinoda and Kanai, 1999; Shinoda, 2003; Maruyama et al., 2003; Tajima et al., 2004; Tanaka et al., 2004; Adachi et al., 2008, 2009a, b, 2011; Matsukusa et al., 2010). To further characterize the sub-haplogroups within N9 and M7a, we used additional primers listed in Table 4.

A total of $1 \mu \mathrm{l}$ of the extracted DNA was used as the template for PCR. Amplifications were carried out in a total reaction volume of $20 \mu \mathrm{l}$ containing of $0.5 \mu \mathrm{M}$ of each primer, and the Multiplex PCR assay kit (TaKaRa) reagents. The PCR conditions were incubation at $94^{\circ} \mathrm{C}$ for $30 \mathrm{sec}$, followed by 42 cycles of $94^{\circ} \mathrm{C}$ for $30 \mathrm{sec}, 54^{\circ} \mathrm{C}$ for $20 \mathrm{sec}$, $72^{\circ} \mathrm{C}$ for $15 \mathrm{sec}$, and $1 \mathrm{cycle}$ of $72^{\circ} \mathrm{C}$ for $10 \mathrm{~min}$. An aliquot $(2.5 \mu \mathrm{l})$ of the PCR product was checked on a $2 \%$ agarose gel, and the remainder $(17.5 \mu \mathrm{l})$ was then purified with Monofas (GL Sciences). The PCR products of SNP analysis were used as template for direct nucleotide sequencing, but we performed cloning of the PCR products of HVR-1 and HVR-2 because of these small quantities. Sequencing reactions were performed with BigDye Terminators v. 1.1 Cycle Sequencing kit (Applied Biosystems, Foster City, CA), and -21M13 and M13RVN primers were used in direct sequencing. All sequencing reactions were carried out using 3130 DNA Sequencer (Applied Biosystems), and the sequence of each region was compared with the revised Cambridge Reference Sequence (CRS) (Andrews et al., 1999).

\section{Contamination precautions}

During each sample-handling step, the following precautions were taken to minimize the risk of contamination. 1. The equipment used (drill, pipettes, centrifuge, vortex machine, and PCR rack) were treated with a DNA contamination removal solution (DNA-AWAY, Molecular 
Table 3. Primers used for PCR amplifications of mitochondrial DNA haplogroup specific SNPs

\begin{tabular}{|c|c|c|c|c|c|}
\hline \multirow{2}{*}{ Haplogroup } & \multirow{2}{*}{$\begin{array}{l}\text { Haplogroup-defining } \\
\text { mutations }\end{array}$} & \multicolumn{2}{|r|}{ Primer } & \multirow{2}{*}{$\begin{array}{l}\text { Nucleotide } \\
\text { positions }^{\mathrm{a}}\end{array}$} & \multirow{2}{*}{$\begin{array}{l}\text { Product } \\
\text { size }\end{array}$} \\
\hline & & ID & Sequence $\left(5^{\prime}-3^{\prime}\right)$ & & \\
\hline \multirow[t]{2}{*}{$\mathrm{M} / \mathrm{D} 5$} & $10400 / 10397$ & M13-L10382 & $(-21 \mathrm{M} 13)^{\mathrm{b}}$ AAGTCTGGCCTATGAGTGACTACAA & $10383-10420$ & 85 \\
\hline & & M13R-H10421 & (M13RVN)'TGAGTCGAAATCATTCGTTTTG & & \\
\hline \multirow[t]{2}{*}{$\mathrm{N}$} & 10873 & M13-L10870 & (-21M13)CCACAGCCTAATTATTAGCATCATC & $10871-10887$ & 67 \\
\hline & & M13R-H10888 & (M13RVN)GCTAAATAGGTTGTTGTTGATTTGG & & \\
\hline \multirow[t]{2}{*}{$\mathrm{A} / \mathrm{G}$} & $4824 / 4833$ & M13-L4812 & (-21M13)TAGCCCCCTTTCACTTCTGA & $4813-4841$ & 68 \\
\hline & & M13R-H4842 & (M13RVN)AAGAAGCAGGCCGGATGT & & \\
\hline \multirow[t]{2}{*}{ B } & $8281-8289$ deletion & M13-L8268 & (-21M13)AATAGGGCCCGTATTTACCCTATA & $8269-8294$ & 78 \\
\hline & & M13R-H8295 & (M13RVN)AGGTTAATGCTAAGTTAGCTTTACAGTG & & \\
\hline \multirow[t]{2}{*}{$\mathrm{D}$} & 5178 & M13-L5171 & (-21M13)ACCCTACTACTATCTCGCACCTGA & $5172-5203$ & 76 \\
\hline & & M13R-H5204 & (M13RVN)CTAGGGAGAGGAGGGTGGAT & & \\
\hline \multirow[t]{2}{*}{$\mathrm{D} 4 / \mathrm{E}$} & $3010 / 3027$ & M13-L3005 & (-21M13)CTCGATGTTGGATCAGGACA & $3006-3028$ & 60 \\
\hline & & M13R-H3029 & (M13RVN)TCGTTGAACAAACGAACCTT & & \\
\hline \multirow[t]{2}{*}{$\mathrm{F}$} & 10310 & M13-L10298 & (-21M13)CCCTACCATGAGCCCTACAA & $10299-10325$ & 72 \\
\hline & & M13R-H10326 & (M13RVN)GGATGATGATTAATAAGAGGGATGA & & \\
\hline \multirow[t]{2}{*}{ M7 } & 9824 & M13-L9816 & (-21M13)TTTTGTAGCCACAGGCTTCC & $9817-9850$ & 74 \\
\hline & & M13R-H9851 & (M13RVN)GGCGGATGAAGCAGATAGTG & & \\
\hline \multirow[t]{2}{*}{$\mathrm{M} 7 \mathrm{a}$} & 2772 & M13-L2742 & (-21M13)GAGAAGACCCTATGGAGCTTTAAT & $2743-2777$ & 83 \\
\hline & & M13R-H2778 & (M13RVN)TAATGCAGGTTTGGTAGTTTAGGA & & \\
\hline \multirow[t]{2}{*}{$\mathrm{M} 7 \mathrm{c}$} & 5442 & M13-L5434 & (-21M13)AAATGACAGTTTGAACATACAAAACC & $5435-5470$ & 86 \\
\hline & & M13R-H5471 & (M13RVN)AAAGGGGAGATAGGTAGGAGTAGC & & \\
\hline \multirow[t]{2}{*}{ M8 } & $15487 \mathrm{~T}$ & M13-L15450 & (-21M13)GCCCTCGGCTTACTTCTCTT & $15451-15488$ & 76 \\
\hline & & M13R-H15489 & (M13RVN)CTGGGTCGCCTAGGAGGT & & \\
\hline \multirow[t]{2}{*}{ M9 } & 3394 & M13-L3376 & M13-GGCATTCCTAATGCTTACCG & $3377-3396$ & 60 \\
\hline & & M13R-H3397 & (M13RVN)GGGCCTTTGCGTAGTTGTAT & & \\
\hline \multirow[t]{2}{*}{ M10 } & 15071 & M13-L15057 & (-21M13)ATCGGGCGAGGCCTATATTA & $15058-15076$ & 59 \\
\hline & & M13R-H15077 & (M13RVN)ATGCCGATGTTTCAGGTTTC & & \\
\hline \multirow[t]{2}{*}{$\mathrm{M} 12 / \mathrm{M} 7 \mathrm{~b}$} & $4170 / 4164$ & M13-L4151 & (-21M13)GAACAGCATACCCCCGATT & $4152-4176$ & 77 \\
\hline & & M13R-H4177 & (M13RVN)TGCTAGGGTGAGTGGTAGGAA & & \\
\hline \multirow[t]{2}{*}{ N9 } & 5417 & M13-L5385 & (-21M13)ТССАССТСААТСАСАСТАСТСС & $5386-5421$ & 78 \\
\hline & & M13R-H5422 & (M13RVN)TGGGGTGGGTTTTGTATGTT & & \\
\hline
\end{tabular}

${ }^{\text {a }}$ Numbers of nucleotide positions are relative to the revised Cambridge reference sequence (rCRS) (Andrews et al., 1999).

b (-21M13) sequence represents 5'-TGTAAAACGACGGCCAGT-3'.

' (M13RVN) sequence represents 5'-TGTGGAATTGTGAGCGG-3'.

BioProducts, San Diego, CA) and with ultraviolet irradiation.

2. Some heat-resistant implements (tube rack made of stainless steel, drill tips, cutting disk, and glass bottle) were treated with dry heat sterilization at $200^{\circ} \mathrm{C}$ for 12 hours.

3. Disposable equipment (tubes and filtered pipette tips) was irradiated with ultraviolet rays.

4. The working area was divided into pre-PCR and postPCR areas.

5. The clean-bench was treated with overnight ultraviolet radiation.

6. Gloves, face masks, and clean-room items (coats, caps, shoes, and socks) were also used when ancient DNA samples were handled.

7. Clean-room items were treated with ultraviolet irradiation overnight.

8. To exclude any possible contamination from modern human DNA, simultaneous negative controls during DNA extraction and PCR amplification steps were added.

\section{Data analysis}

To investigate the relationship between the Tohoku Jomon people and the other ancient and modern East Asians, we compared mtDNA haplogroup frequencies (Appendix 1) using Arlequin v. 3.11 (Excoffier et al., 2005). For pairwise population comparisons, the $F$ st formula used in Arlequin is identical to the weighted average $F$-statistic over loci, $\theta w$, defined by Weir and Cockerham (1984) (Michalakis and Excoffier, 1996). The equation to calculate $F$ st-values is as follows:

$$
\begin{aligned}
& \hat{\theta}_{W}=\frac{\sum_{u} a_{u}}{\sum_{u}\left(a_{u}+b_{u}+c_{u}\right)} \\
& a_{u}=\frac{\bar{n}}{n_{c}}\left\{s^{2}-\frac{1}{\bar{n}-1}\left[\bar{p}(1-\bar{p})-\frac{r-1}{r} s^{2}-\frac{1}{4} \bar{h}\right]\right\}
\end{aligned}
$$


Table 4. Primers used for PCR amplifications of mitochondrial DNA sub-haplogroup specific SNPs

\begin{tabular}{|c|c|c|c|c|c|}
\hline \multirow{2}{*}{ Haplogroup } & \multirow{2}{*}{$\begin{array}{l}\text { Haplogroup-defining } \\
\text { mutations }\end{array}$} & \multicolumn{2}{|r|}{ Primer } & \multirow{2}{*}{$\begin{array}{l}\text { Nucleotide } \\
\text { positions }^{\mathrm{a}}\end{array}$} & \multirow{2}{*}{$\begin{array}{l}\text { Product } \\
\text { size }\end{array}$} \\
\hline & & ID & Sequence $\left(5^{\prime}-3^{\prime}\right)$ & & \\
\hline \multirow[t]{4}{*}{ M7a1 } & 14364 & M13-L14357 & (-21M13) $)^{\mathrm{b} C C A C C C C A T C A T A C T C T T T C A ~}$ & $14358-14398$ & 83 \\
\hline & & M13R-H14399 & $(\mathrm{M} 13 \mathrm{RVN})^{\mathrm{c}}$ GGTTGAGGTCTTGGTGAGTGT & & \\
\hline & 16324 & M13-L16302 & (-21M13)САAАCCТАСССАСССТТААСА & $16303-16345$ & 84 \\
\hline & & M13R-H16346 & (M13RVN)GGGACGAGAAGGGATTTGAC & & \\
\hline \multirow[t]{4}{*}{$\mathrm{M} 7 \mathrm{a} 2$} & 15422 & M13-L15401 & (-21M13)CCTCCCATTCCGATAAAATCA & $15402-15426$ & 65 \\
\hline & & M13R-H15427 & (M13RVN)AAGTAAGCCGAGGGCGTCT & & \\
\hline & 16140 & M13-L16119 & (-21M13)ATTACTGCCAGCCACCATGA & $16120-16169$ & 90 \\
\hline & & M13R-H16170 & (M13RVN)AGGGGGTTTTGATGTGGATT & & \\
\hline \multirow[t]{2}{*}{ N9a } & 5231 & M13-L5217 & (-21M13)AАТТССАТССАСССТССТСТ & $5218-5237$ & 58 \\
\hline & & M13R-H5238 & (M13RVN)GGGCAAAAAGCCGGTTAG & & \\
\hline \multirow[t]{2}{*}{$\mathrm{N} 9 \mathrm{~b}$} & 13183 & M13-L13147 & (-21M13)CCCCCTAGCAGAAAATAGCC & $13148-13187$ & 80 \\
\hline & & M13R-H13188 & (M13RVN)AGACTGCTGCGAACAGAGTG & & \\
\hline \multirow[t]{2}{*}{ N9b1 } & 12501 & M13-L12492 & (-21M13)TCAGTCTCTTCCCCACAACA & $12493-12523$ & 71 \\
\hline & & M13R-H12524 & (M13RVN)GGCTCAGTGTCAGTTCGAGA & & \\
\hline \multirow[t]{2}{*}{ N9b2 } & 16294 & M13-L16292 & (-21M13)CACTAGGATACCAACAAACCTACCC & $16293-16326$ & 84 \\
\hline & & M13R-H16327 & (M13RVN)TTTGACTGTAATGTGCTATGTACGG & & \\
\hline \multirow[t]{2}{*}{ N9b3 } & 14996 & M13-L14965 & (-21M13)CCCACATCACTCGAGACGTA & $14966-14997$ & 72 \\
\hline & & M13R-H14998 & (M13RVN)AGAATATTGAGGCGCCATTG & & \\
\hline \multirow[t]{2}{*}{$\mathrm{Y}$} & 8392 & M13-L8380 & (-21M13)CAGTGAAATGCCCCAACTAAAT & $8381-8394$ & 59 \\
\hline & & M13R-H8395 & (M13RVN)GGAGTATGGGGGTAATTATGGTG & & \\
\hline
\end{tabular}

${ }^{\text {a }}$ Numbers of nucleotide positions are relative to the revised Cambridge reference sequence (rCRS) (Andrews et al., 1999).

b (-21M13) sequence represents 5'-TGTAAAACGACGGCCAGT-3'.

c (M13RVN) sequence represents 5'-TGTGGAATTGTGAGCGG-3'.

$$
\begin{aligned}
& b_{u}=\frac{\bar{n}}{\bar{n}-1}\left[\bar{p}(1-\bar{p})-\frac{r-1}{r} s^{2}-\frac{2 \bar{n}-1}{4 \bar{n}} \bar{h}\right] \\
& c_{u}=\frac{1}{2} \bar{h}
\end{aligned}
$$

where $a_{\mathrm{u}}, b_{\mathrm{u}}$, and $c_{\mathrm{u}}$ are the observed components of variance ( $a_{\mathrm{u}}$ for between populations, $b_{\mathrm{u}}$ for between individuals within populations, and $c_{\mathrm{u}}$ for between gametes within individuals); $n$ bar is the average sample size; $n_{\mathrm{c}}$ is the squared coefficient of variation of sample sizes; $p$ bar is the average sample frequency of alleles; $s^{2}$ is the sample variance of allele frequencies over populations; $h$ bar is the average heterozygote frequency for alleles. For further details, see Weir and Cockerham (1984).

Three ancient populations, the Hokkaido (Adachi et al., 2011), Tohoku (present study; Adachi et al., 2009a), and Kanto Jomon (Shinoda and Kanai, 1999; Shinoda, 2003), the Okhotsk people (Sato et al., 2009), and the following 14 modern populations were compared: Ainu (Tajima et al., 2004), mainland Japanese (Maruyama et al., 2003), Ryukyuan (Umetsu et al., 2005), Korean (Lee et al., 2006), northern Chinese (Yao et al., 2002), Yangtze River region Chinese (Yao et al., 2002), southern Chinese (Yao et al., 2002), Aboriginal Taiwanese (Trejaut et al., 2005), northern Siberians (Starikovskaya et al., 1998), Kamchatkans (Schurr et al., 1999), Ulchi (Starikovskaya et al., 2005), Udegey (Starikovskaya et al., 2005), Nivkhi (Starikovskaya et al., 2005), and Negidal (Starikovskaya et al., 2005). Principal component analysis (PCA) scatterplots and phylogenetic networks were constructed with $\mathrm{R}$ ( $\mathrm{R}$ Development Core Team, 2010) and splitstree4 (Huson and Bryant, 2006), respectively, based on pairwise $F$ st-values.

\section{Results and Discussion}

\section{PCR and SNP typing}

We successfully determined the mtDNA haplogroup of all four individuals that we examined (Table 5), using the primer pairs targeting short DNA segments (58-90 bp). In each individual, all SNP sites were consistent with previously observed haplogroups, and this thus reduces the chance of contamination. When we used the primer pairs targeting long DNA segments (158-195 bp) in the analysis of HVR, the amplification efficiency and quantity of PCR products decreased dramatically, possibly due to the sample conditions. This corresponds to the observations of Pääbo et al. (2004) and Haak et al. (2010). To estimate the level of modern DNA contamination, long PCR products were sequenced with cloning. In these analysis, some PCR products contained sequences that were inconsistent with the SNP analysis. This indicates that, to reduce the effect of contamination in the analysis of ancient DNA, focusing on short DNA regions is better, and we need to reduce the number of PCR cycles.

Population comparison based on haplogroup frequencies

Two of the four Sanganji Jomon individuals belonged to haplogroup N9b (Table 5, Table 6). Haplogroup N9b has 
Table 5. Observed nucleotide mutations of four Sanganji Jomon individuals

\begin{tabular}{|c|c|c|c|c|c|c|}
\hline \multirow{4}{*}{ Haplogroup } & \multirow{4}{*}{ Nucleotide position $^{\mathrm{a}}$} & Sample & Sanganji131421-1 & Sanganji131421-2 & Sanganji131421-3 & Sanganji131464 \\
\hline & & Sex & $\mathrm{F} ?$ & M & M & $\mathrm{f}$ \\
\hline & & Tooth ablation type & 0 & 0 & $4 \mathrm{I} ?$ & $2 \mathrm{C}$ \\
\hline & & $\mathrm{rCRS}^{\mathrm{b}}$ & & & & \\
\hline $\mathrm{M}$ & 10400 & $\mathrm{C}$ & $\mathbf{T}$ & $\mathbf{T}$ & $\mathrm{C}$ & $\mathrm{C}$ \\
\hline $\mathrm{N}$ & 10873 & $\mathrm{~T}$ & $\mathbf{C}$ & C & $\mathbf{T}$ & $\mathbf{T}$ \\
\hline A & 4824 & A & A & A & A & A \\
\hline B & $8281-8289$ deletion & 2 & 2 & 2 & 2 & 2 \\
\hline $\mathrm{D}$ & 5178 & $\mathrm{C}$ & $\mathrm{C}$ & $\mathrm{C}$ & $\mathrm{C}$ & $\mathrm{C}$ \\
\hline D4 & 3010 & $\mathrm{G}$ & ND & ND & ND & ND \\
\hline D5 & 10397 & $\mathrm{~A}$ & $\mathrm{~A}$ & $\mathrm{~A}$ & $\mathrm{~A}$ & $\mathrm{~A}$ \\
\hline $\mathrm{E}$ & 3027 & $\mathrm{~T}$ & ND & ND & ND & ND \\
\hline $\mathrm{F}$ & 10310 & G & G & $\mathrm{G}$ & G & $\mathrm{G}$ \\
\hline G & 4833 & A & A & A & A & $\mathrm{A}$ \\
\hline M7 & 9824 & $\mathrm{~T}$ & $\mathrm{C}$ & C & $\mathrm{T}$ & $\mathrm{T}$ \\
\hline M7a & 2772 & $\mathrm{C}$ & $\mathbf{T}$ & $\mathbf{T}$ & - & - \\
\hline M7a1 & 14364 & G & G & G & - & - \\
\hline & 16324 & $\mathrm{~T}$ & $\mathrm{~T}$ & $\mathrm{~T}$ & - & - \\
\hline M7a2 & 15422 & A & G & G & - & - \\
\hline & 16140 & $\mathrm{~T}$ & C & $\mathrm{C}$ & - & - \\
\hline M7b & 4164 & $\mathrm{C}$ & $\mathrm{C}$ & $\mathrm{C}$ & $\mathrm{C}$ & $\mathrm{C}$ \\
\hline M7c & 5442 & $\mathrm{~T}$ & ND & ND & - & - \\
\hline M8 & $15487 \mathrm{~T}$ & $\mathrm{~A}$ & A & $\mathrm{A}$ & $\mathrm{A}$ & $\mathrm{A}$ \\
\hline M9 & 3394 & $\mathrm{~T}$ & ND & ND & ND & ND \\
\hline M10 & 15071 & $\mathrm{~T}$ & $\mathrm{~T}$ & $\mathrm{~T}$ & $\mathrm{~T}$ & $\mathrm{~T}$ \\
\hline M12 & 4170 & A & A & A & A & A \\
\hline N9 & 5417 & G & G & G & $\mathbf{A}$ & $\mathbf{A}$ \\
\hline N9a & 5231 & G & - & - & $\mathrm{G}$ & $\mathrm{G}$ \\
\hline $\mathrm{N} 9 \mathrm{~b}$ & 13183 & A & - & - & G & $\mathbf{G}$ \\
\hline N9b1 & 12501 & G & - & - & G & G \\
\hline N9b2 & 16294 & $\mathrm{C}$ & - & - & $\mathrm{C}$ & - \\
\hline N9b3 & 14996 & G & - & - & G & G \\
\hline $\mathrm{Y}$ & 8392 & G & 一 & - & ND & ND \\
\hline HVR & $128-256$ & & ND & 146 & ND & CRS \\
\hline & $15999-16141$ & & ND & ND & ND & ND \\
\hline & $16121-16238$ & & ND & ND & ND & ND \\
\hline & $16209-16366$ & & ND & ND & ND & $16256, \mathbf{1 6 2 9 4}$ \\
\hline Haplogroup & & & M7a2 & M7a2 & N9b* & N9b2 \\
\hline
\end{tabular}

ND, not determined; - , not analyzed; diagnostic polymorphisms are emphasized by bold type. Haplogroup B has a 9 bp (CCCCCTCTA) deletion. ' 1 ' denotes the presence of the 9 bp deletion, and ' 2 ' denotes nondeletion (i.e. two repeats of the 9 bp fragment).

${ }^{a}$ Numbers of nucleotide positions are relative to the revised Cambridge reference sequence (rCRS) (Andrews et al., 1999).

${ }^{\mathrm{b}}$ The sequences of rCRS

been observed in the northern Jomon populations at high frequencies: Hokkaido Jomon, 64.8\% (Adachi et al., 2011); Tohoku Jomon, 63.2\% (Adachi et al., 2009a); and we found this haplogroup in high frequency $(50.0 \%)$ in the Sanganji Jomon, although based on a small sample size. On the contrary, the frequency of haplogroup N9b was low in the Kanto Jomon at 5.6\% (Shinoda and Kanai, 1999, Shinoda, 2003). In modern populations, haplogroup N9b is present in the Japanese archipelago at low frequencies $(<10 \%)$ (Maruyama et al., 2003; Tajima et al., 2004; Umetsu et al., 2005), but at a high frequency $(30.4 \%)$ in the Udegey from southern Siberia. It seems that haplogroup N9b was one of the main haplogroups in ancient and modern Northeast Asian populations.

We further subdivided the haplogroup N9b observed in the two Sanganji Jomon individuals using specific primers into four sub-haplogroups (N9b1, N9b2, N9b3, and N9b*) (Table 4). Samples which could not be designated to subhaplogroups N9b1, N9b2, and N9b3 were classified as subhaplogroup N9b*. Of the two Sanganji Jomon samples, one was classified as sub-haplogroup N9b2 and another was classified as sub-haplogroup N9b*. In the Hokkaido Jomon, although sub-haplogroup N9b* was observed, subhaplogroup N9b2 has so far not been observed. The Sanganji results may hint at some population differentiation among the northern Jomon populations.

Haplogroup M7a is classified into three sub-haplogroups, M7a1, M7a2, and M7a*. Individuals who were not classified into sub-haplogroups M7a1 and M7a2 were classified into 

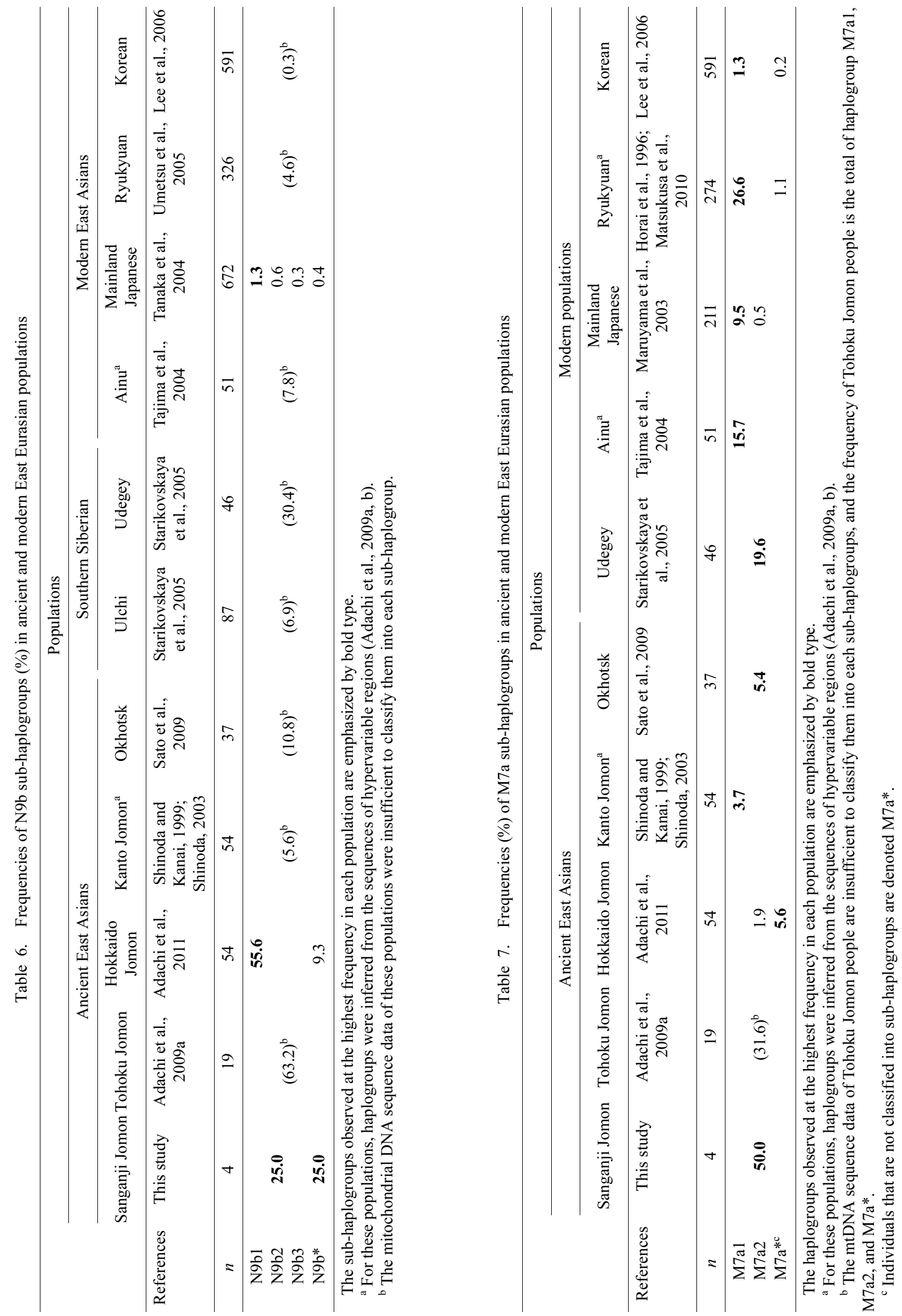
sub-haplogroup M7a*. We found that two Sanganji individuals belonged to haplogroup M7a2 (Table 5, Table 7). In modern populations, haplogroup M7a1 was observed in modern Japanese populations at a high frequency: Ainu, $15.7 \%$ (Tajima et al., 2004); mainland Japanese, 9.5\% (Maruyama et al., 2003); Ryukyuan, 26.6\% (Horai et al., 1996, Matsukusa et al., 2010). However, haplogroup M7a2 was scarcely observed in the mainland Japanese $(0.5 \%)$, and this haplogroup was not observed in the Ryukyuan. On the contrary, haplogroup M7a2 was observed in the Udegey from southern Siberia at high frequency (19.6\%, Starikovskaya et al., 2005).

In ancient East Asian populations, haplogroup M7a (which includes M7a1, M7a2, and M7a*) is widely observed in the Jomon people (Hokkaido Jomon, 7.4\%; Tohoku Jomon, 31.6\%; Kanto Jomon, 3.7\%). That the Sanganji Jomon (present study) also had this haplogroup apparently at high frequency $(50.0 \%)$ supports the suggestion of Adachi et al. (2009b) that haplogroup M7a is a putative 'Jomon genotype.' However, we have now identified the occurrence of sub-haplogroup M7a2 for the first time in the Tohoku Jomon, which enables some further considerations.

Although the currently available data is still limited, interestingly, the frequencies of haplogroups M7a1 and M7a2 appear quite different among the Jomon people (Table 7). This may indicate that during the later Jomon period, M7al was mainly distributed in the middle to southern part of the Japanese archipelago, and haplogroup M7a2 (and also M7a*) was distributed further north, from the Tohoku and Hokkaido regions of the Japanese archipelago and southern Siberia. Adachi et al. (2011) suggested that haplogroup M7a was of southern origin, and that this haplogroup was introduced to Japan around the last glacial maximum (LGM). If we accept this suggestion, haplogroup M7a2, which is observed in the northern Jomon people, might have originated after the introduction of M7a into the Japanese archipelago. The sub-haplotype then subsequently became distributed further northward by migration, and must have reached southern Siberia.

The tooth ablation type of Sanganji individuals 13142-1 and $13142-2$ was both probably the 0-type (only the upper canine extracted, no mandibular tooth extraction), which suggests an in-group status of the individuals according to Harunari's (2002) interpretation of ablation patterns. On the other hand, individual 13142-3 did not exhibit a clear pattern and 131464 was the 2C-type, which suggests an out-group status. Therefore, individuals 13142-1 and 13142-2, both possibly born at Sanganji and with the same haplotype, could have been relatives. However, since sub-haplogroup M7a2 might have been the major type in that region, it is also possible that they shared the same haplotype without having any genealogical relationship.

The genetic transition from the Jomon people to modern Japanese is explained by the 'dual structure model,' according to which a substantial number of Yayoi people migrated into the Japanese archipelago via the Korean peninsula about 3000 years ago, and admixed with Jomon people (Hanihara, 1991). This model also suggests that the effect of the Yayoi immigrants is small in the Ainu and Ryukyuan peoples, who live at the margins of the Japanese archipelago and retain more Jomon components than the mainland Japanese. In fact, this expected pattern was recently observed from the comparison of genome-wide autosomal SNP data for the Ainu, the Ryukyuan, and the mainland Japanese populations (Japanese Archipelago Human Population Genetics Consortium, 2012). Therefore, high frequencies of the 'Jomon genotype' (haplogroup N9b and M7a) in the Ainu and Ryukyuan peoples have been considered to partially support this model (Adachi et al., 2009b). Thus, it is expected that the Ainu people who live in Hokkaido, the northernmost Japanese archipelago, would have haplogroups M7a* and $\mathrm{M} 7 \mathrm{a} 2$ in high frequencies, because the northern Jomon populations have been so far shown to have these haplogroups. However, the Ainu people have only haplogroup M7a1 (Table 7). This may indicate either sample bias, or that the haplogroup M7a of the Ainu was not derived from the indigenous northern Jomon genotype, and that this haplogroup was introduced into the Ainu population after the Jomon period. The latter interpretation implies that the genetic effect from mainland Japan after the Jomon period was stronger than previously considered.

To investigate the relationships between the Jomon people from the Tohoku region (Sanganji Jomon, present study; the Tohoku Jomon, Adachi et al., 2011) and other East and Northeast Asian ancient and modern populations, a statistical analysis based on haplogroup frequencies (Appendix 1) was performed. In this analysis, we merged sub-haplogroups N9b1, N9b2, N9b3, and N9b* into haplogroup N9b, and sub-haplogroups M7a1, M7a2, and M7a* into haplogroup M7a, because sub-haplogroup frequency data were missing in some populations used in the statistical analysis (Table 6, Table 7). The approximate geographical locations of these populations are shown in Figure 1 and Figure 2.

Within the Japanese archipelago, contrasting opinions on the population structure of the Jomon have been proposed: the Jomon people were relatively homogeneous (Dodo, 1982; Yamaguchi, 1982; Kondo, 1994; Ossenberg et al., 2006; Matsumura, 2007) or heterogeneous (Adachi et al., 2009a, b; Hanihara and Ishida, 2009; Nakashima et al., 2010). When comparing the ancient populations of the Japanese archipelago (Kanto, Tohoku, and Hokkaido Jomons and Okhotsk), the population differentiation test demonstrated that they were statistically different from each other (highest $P$-value was 0.007 between the Tohoku and Hokkaido Jomon). This indicates inter-regional heterogeneity of the ancient Japanese archipelago populations, consistent with results of recent genetic (Adachi et al., 2009a, b) and morphological (Hanihara and Ishida, 2009; Nakashima et al., 2010) research.

Next, in order to obtain, for the first time, an indication of overall genetic similarities of the Jomon regional populations as seen from the mtDNA haplotypes, we computed $F$ st values between population pairs. The $P$-values between the Tohoku Jomon and the other ancient or modern comparative populations were less than $5 \%$, based on 100 permutations of the Arlequin software. The results showed a close genetic similarity between the Tohoku and Hokkaido Jomon people $(F$ st $=0.061, P=0.036 \pm 0.015)($ Appendix 2$)$, and support previous interpretations that the Jomon ancestors of the northern part of Japan (Hokkaido) might have expanded 


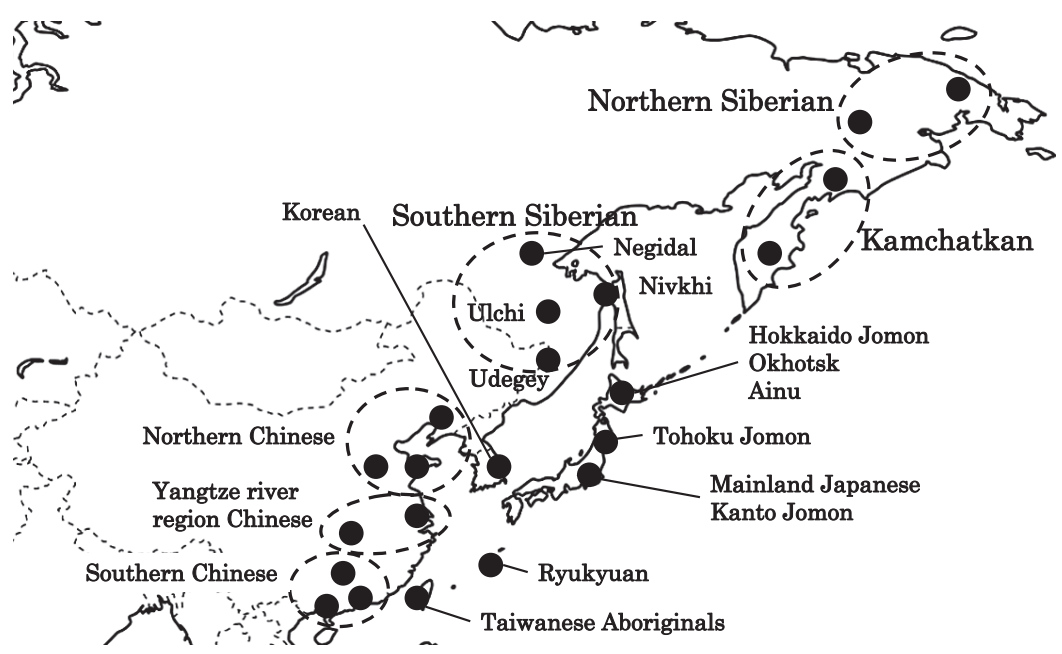

Figure 2. A map of East Eurasia and geographic locations of the East Asian and Siberian populations compared in the present study.

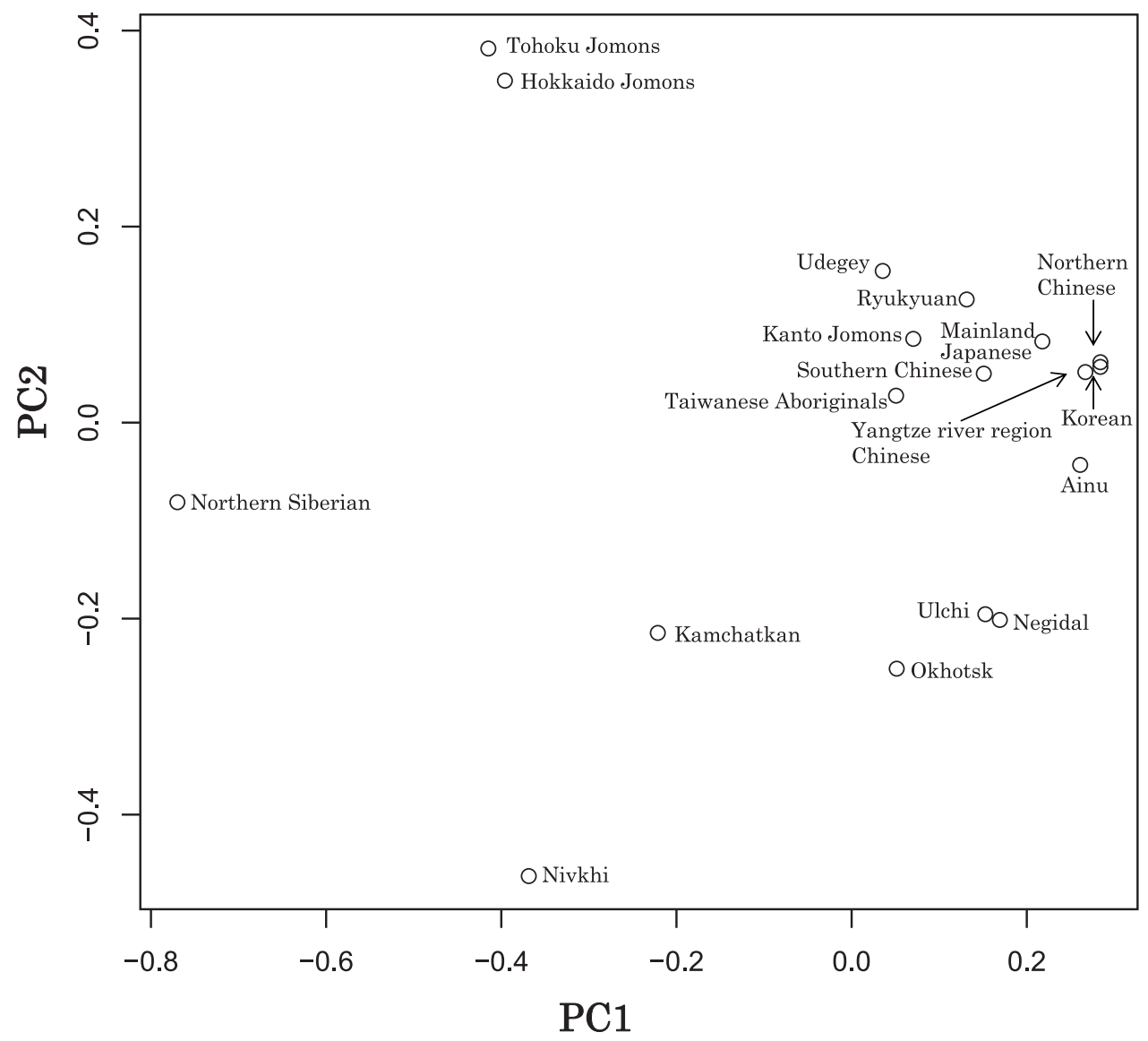

Figure 3. Principle Component Analysis of 18 East Asian populations based on Fst values.

southward to Honshu Island with a series of bottlenecks (Hanihara and Ishida, 2009; Nakashima et al., 2010). However, genetic similarity between the Tohoku Jomon and the geographically adjacent Kanto Jomon was not observed $(F$ st $=0.268)$; the differences are shown in the PCA plot and the phylogenetic network (Figure 3, Figure 4). These results are an indication of genetic differences between the Kanto and northern Jomon populations.

Adachi et al. (2009a) mentioned that three regional Jomon populations shared some haplogroups (M7a and N9b), and that genetic similarity decreased gradually with increased geographical distance. However, since sub-haplogroups $\mathrm{M} 7 \mathrm{a} 2$ and N9b2 have so far not been shown to be shared between the Tohoku and Kanto Jomon people, it may be 


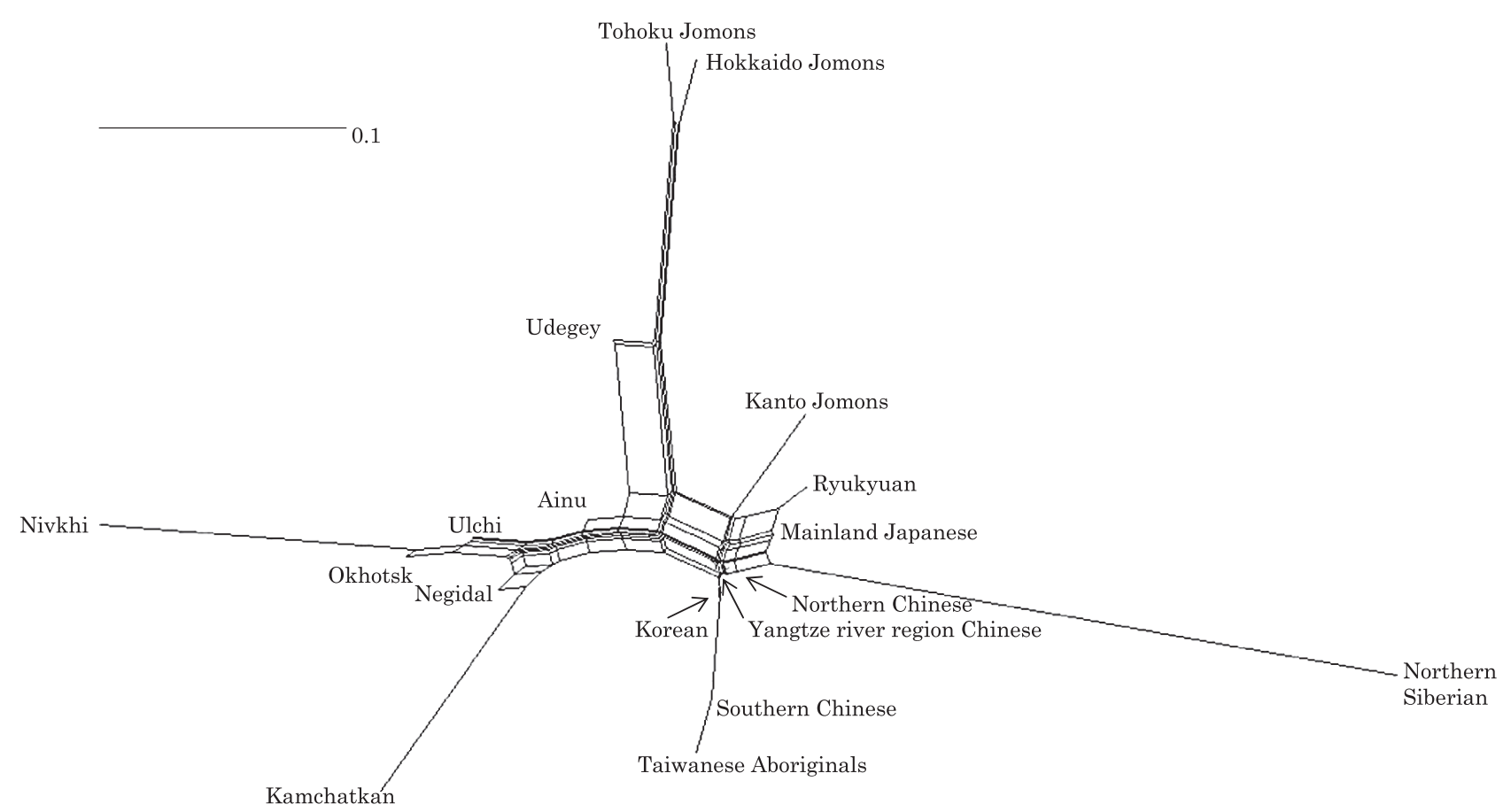

Figure 4. Phylogenetic network of 18 East Asian populations based on $F$ st values.

that, in terms of the maternal lineage, the gene flow between the geographically close Tohoku and Kanto regions was limited in the Jomon period. In addition, in the population comparison analysis, although we found genetic similarity between the Hokkaido and Tohoku Jomon, so far they lack shared haplogroups at the sub-haplogroup level (M7a*, D4h2, and G1b of the Hokkaido Jomon were not seen in the Tohoku Jomon, and N9b2 and D4b of the Tohoku Jomon were not seen in the Hokkaido Jomon). Again, this may be indicating comparatively limited gene flow in the Jomon period. This interpretation is consistent with the results of the population differentiation test, and the observation of inter-regional heterogeneity among the ancient Japanese archipelago populations. However, the above interpretations need to be confirmed and refined by larger samples of subhaplogroup determinations and better temporal control of the Jomon materials.

Compared to modern East Asian populations, the Tohoku and Hokkaido Jomon people were genetically close to the Udegey of southern Siberia (Udegey and Tohoku Jomon, $F$ st $=0.088, P=0.01 ; \quad$ Udegey and Hokkaido Jomon, $F$ st $=0.138, P=0.00$ ) (Appendix 2). The Udegey is also geographically closer to the Jomon populations than are the other southern Siberian populations (Figure 2). In the phylogenetic network shown in Figure 4, based on shared mtDNA haplogroups M7a and N9b (Appendix 1), it seems possible that the Udegey represents admixture of southern Siberian populations and the northern (Hokkaido and Tohoku) Jomon people. This implies some degree of gene flow between the Udegey people ancestors and the northern Jomon. Moreover, as we mentioned earlier, haplogroups N9b and M7a2 are hardly observed in the other East Asian populations except in the Japanese archipelago (Table 6, Table 7). One in- terpretation would be that a northern population with haplogroups N9b and M7a2 migrated into the Tohoku region via Hokkaido, although a southern origin has been considered for the M7a haplotype (see above for discussion of the southern haplogroup hypothesis). This would be compatible with the conclusion of previous studies that the Jomon people were (largely) of northern origin (Nei, 1995; Omoto and Saitou, 1997; Hanihara and Ishida, 2009; Nakashima et al., 2010; Adachi et al., 2011).

The Sanganji results and related analyses presented above suggest that the history of the Jomon people is more complex than previously considered (see also Adachi et al., 2011). Our knowledge of Tohoku and Kanto Jomon subhaplogroup representations is still limited, and we do not know the genetic background of the Jomon people from west of the Kanto region or the Sea of Japan coastal areas. Therefore, further data accumulation, not only mitochondrial DNA but also nuclear DNA (Sato et al., 2010; Kazuta et al., 2011), and ancient DNA analysis based on larger samples with both adequate temporal control and more extensive geographical regions are necessary to clarify an apparently complex Jomon population history.

Moreover, since next-generation sequencing technology makes it possible to analyze tiny amounts of ancient DNA (e.g. Green et al., 2010), it is quickly becoming practicable to analyze not only Jomon mtDNA, but also nuclear DNA, which contains much more genetic information. Since the success rate of mtDNA haplotyping of four Sanganji Jomon samples was $100 \%$, skeletal remains materials from sites such as Sanganji may also contain nuclear DNA. With this prospect of an expanded range of materials suitable for ancient nuclear DNA analysis with the emergence of nextgeneration sequencing, further studies on the Tohoku and 
other Jomon materials may enable a better resolution to the issues discussed herein.

\section{Conclusion}

We (H.K.-K. and N.S.) initially suspected that the DNA analysis of materials such as those of the Sanganji Jomon would be difficult because of their prolonged storage in museums. However, albeit with a small sample size of four, the success rate of mtDNA haplogroup detection increased to $100 \%$ when focusing on short DNA regions.

Our observation of genetic similarity between the Tohoku Jomon and some of the indigenous southern Siberian peoples is compatible with previous interpretations that the Jomon people originated in Northeast Asia. However, statistical analysis of Jomon populations suggests: (1) the existence of inter-regional heterogeneity within the Jomon people; (2) genetic similarity among the two northern Jomon populations (Tohoku and Hokkaido) much more so than with the Kanto Jomon, implying comparatively limited gene flow between the Kanto and more northern regions; and (3) despite their relative closeness, the presence of subhaplotype differences between the two northern Jomon populations. The emerging implication seems that the history of the Jomon people may have been more complex than previously considered.

In the modern Japanese, mtDNA haplogroups $\mathrm{N} 9 \mathrm{~b}$ and M7a2, common in the Sanganji and Hokkaido Jomons, are uncommon. Therefore, it seems that the genetic influence of the northern Jomon populations to the modern mainland Japanese is limited in the maternal linage. However, the samples analyzed in the present study are limited, and current and previous reports are confined mostly to Jomon skeletal materials of the east coast of the Tohoku region. In order to clarify the characteristics of the Tohoku Jomon as well as their genetic influence on modern populations, larger and geographically wider-based samples need to be investigated.

\section{Acknowledgments}

We would like to thank Dr. Shintaroh Ueda, Department of Biological Sciences, The University of Tokyo, Dr. Ryuichi Masuda, Department of Biological Sciences, Hokkaido University, and Dr. Kenta Sumiyama, National Institute of Genetics, for their suggestions about our experiments. We are also grateful to Drs. Tomoya Baba, Katsuhiko Yanagihara, and Yasuo Shirakibara of the National Institute of Genetics, for kindly providing us access to their experimental rooms.

\section{References}

Adachi N., Shinoda K., and Umetsu K. (2008) Mitochondrial DNA analysis of the Jomon skeletons excavated from the Tohoku region of Japan. DNA Polymorphism, 16: 287-290 (in Japanese).

Adachi N., Shinoda K., and Umetsu K. (2009a) Mitochondrial DNA analysis of the Jomon skeletons excavated from the northern part of Japan. DNA Polymorphism, 17: 265-269 (in Japanese).

Adachi N., Shinoda K., Umetsu K., and Matsumura H. (2009b) Mitochondrial DNA analysis of Jomon skeletons from the
Funadomari site, Hokkaido, and its implication for the origins of native American. American Journal of Physical Anthropology, 138: 255-265.

Adachi N., Shinoda K., Umetsu K., Kitano T., Matsumura H., Fujiyama R., Sawada J., and Tanaka M. (2011) Mitochondrial DNA analysis of Hokkaido Jomon skeletons: remnants of archaic maternal lineages at the southwestern edge of former Beringia. American Journal of Physical Anthropology, 146: 346-360.

Andrews R.M., Kubacka I., Chinnery P.F., Lightowlers R.N., Turnbull D.M., and Howell N. (1999) Reanalysis and revision of the Cambridge reference sequence for human mitochondrial DNA. Nature Genetics, 23: 147.

Dodo Y. (1982) A metric analysis of Jomon crania from the Tohoku district. The Journal of Anthropological Society of Nippon, 90 (Suppl.): 119-128 (in Japanese with English summary).

Endo Y. and Endo B. (1979) Catalogue of skeletal remains from Neolithic Jomon period in Japan preserved in The University Museum, The University of Tokyo. The University Museum, The University of Tokyo, Material Reports, 3 (in Japanese).

Excoffier L., Laval G., and Schneider S. (2005) Arlequin ver. 3.0: an intergrated software pakage for population genetics data analysis. Evolutionary Bioinfomatics Online, 1: 47-50.

Fukushima Museum (1988) Sanganji shell mound, investigative report from Fukushima Museum, No. 17 (in Japanese).

Funahashi K. (2010) Ritual Tooth Extraction and Social Groupings. Suirensha, Tokyo (in Japanese).

Green R.E., Krause J., Briggs A.W., Maricic T., Stenzel U., Kircher M., Patterson N., Li H., Zhai W., Fritz M.H., Hansen N.F., Durand E.Y., Malaspinas A., Jensen J.D., MarquwsBonet T., Alkan C., Prüfer K., Meyer M., Hernán A. Burbano, Good J.M., Schultz R., Aximu-Petri A., Butthof A., Höber B., Höffner B., Siegemund M., Weihmann A., Nusbaum C., Lander E.S., Russ C., Novod N., Affourtit J., Egholm M., Verna C., Rudan P., Brajkovic D., Kucan Ž., Gušic I., Doronichev V.B., Golovanova L.V., Lalueza-Fox C., Rasilla M., Fortea J., Rosas A., Schmitz R.W., Johnson P.L.F., Eichler E.E., Falush D., Birney E., Mullikin J.C., Slatkin M., Nielsen R., Kelso J., Lachmann M., Reich D., and Pääbo S. (2010) A draft sequence of the Neandertal genome. Science, 328: 710-722.

Haak W., Balanovsky O., Sanchez J.J., Koshel S., Zaporozhchenko V., Adler C.J., Sarkissian C.S.I., Brandt G., Schwarz C., Nicklisch N., Dresely V., Fritsch B., Balanovska E., Villems R., Meller H., Alt K.W., Cooper A., and the Genographic Consortium (2010) Ancient DNA from European early Neolithic farmers reveals their Near Eastern affinities. PLoS Biology, 8(11): e1000536.

Hanihara K. (1991) Dual structure model for the population history of the Japanese. Japan Review, 2: 1-33.

Hanihara T. and Ishida H. (2009) Regional difference in craniofacial diversity and the population history of Jomon Japan. American Journal of Physical Anthropology, 139: 311-322.

Harunari H. (2002) A Study of Jomon Society. Hanawa Syobo Company Limited, Tokyo (in Japanese).

Horai S., Hayasaka K., Murayama K., Wate N., Koike H., and Nakai N. (1989) DNA amplification from ancient human skeletal specimens and their sequence analysis. Proceedings of Japan Academy, 65: 229-233.

Horai S., Kondo R., Murayama K., Hayashi S., Koike H., and Nakai N. (1991) Phylogenetic affiliation of ancient and contemporary humans inferred from mitochondrial DNA. Philosophical Transactions of the Royal Society of London B, 333: 409-417.

Horai S., Murayama K., Hayasaka K., Matsubayashi S., Hattori Y., Fucharoen G., Harihara S., Park K.S., Omoto K., and Pan I.H. (1996) mtDNA polymorphism in East Asian populations, with special reference to the peopling of Japan. American Journal of Human Genetics, 59: 579-590. 
Huson D.H. and Bryant D. (2006) Application of phylogenetic networks in evolutionary studies. Molecular Biology and Evolution, 23: 254-267.

Imamura K. (1996) Prehistoric Japan: New Perspectives on Insular East Asia. University of Hawaii Press, Honolulu.

Japanese Archipelago Human Population Genetics Consortium [Jinam T., Nishida N., Hirai M., Kawamura S., Oota H., Umetsu K., Kimura R., Ohashi J., Tajima A., Yamamoto T., Tanabe H., Mano S., Suto Y., Kaname T., Naritomi K., Yanagi K., Niikawa N., Omoto K., Tokunaga K., and Saitou N.] (2012) The history of human populations in the Japanese Archipelago inferred from genome-wide SNP data with a special reference to the Ainu and the Ryukyuan populations. Journal of Human Genetics, 57 (in press).

Kazuta H., Sato T., Dodo Y., Matsumura H., Amano T., Ishida H., and Masuda R. (2011) Genotype frequencies of the ABCC11 gene in 2000-3000-year-old human bones from the EpiJomon and Jomon sites in Hokkaido, Japan. Anthropological Science, 119: 81-86.

Kobayashi K. (2008) The Period of Jomon Pottery in Eastern Japan. Complete Guide to Jomon Pottery. UMpromotion, pp. 896-903 (in Japanese).

Kondo O. (1994) The skulls of Ubayama Shell-mounds. II. An analysis of intra- and inter-regional variation of the Jomon population. Anthropological Science, 102: 59-74.

Lee H.Y., Yoo J.E., Park M.J., Chung U., and Shin K.J. (2006) Mitochondrial DNA control region sequences in Korean: identification of useful variable sites and phylogenetic analysis for mtDNA data quality control. International Journal of Legal Medicine, 120: 5-14.

Maruyama S., Minaguchi K., and Saitou N. (2003) Sequence polymorphisms of the mitochondrial DNA control region and phylogenetic analysis of mtDNA lineages in the Japanese population. International Journal of Legal Medicine, 117: $218-225$.

Matsukusa H., Oota H., Haneji K., Toma T., Kawamura S., and Ishida H. (2010) A genetic analysis of the Sakishima Islanders reveals no relationship with Taiwan Aborigines but shared ancestry with Ainu and Main-Island Japanese. American Journal of Physical Anthropology, 142: 211-223.

Matsumura H. (2007) Non-metric dental trait variation among local sites and regional groups of the Neolithic Jomon period, Japan. Anthropological Science, 115: 25-33.

Matsumura H., Ishida H., Amano T., Ono H., and Yoneda M. (2009) Biological affinities of Okhotsk-culture people with East Siberians and Arctic people based on dental characteristics. Anthropological Science, 117: 121-132.

Melchior L., Lynnerup N., Siegismund H.R., Kivisild T., and Dissing J. (2010) Genetic diversity among ancient Nordic populations. PLoS ONE, 5(7): e11898.

Michalakis Y. and Excoffier L. (1996) A generic estimation of population subdivision using distances between alleles with special reference to microsatellite loci. Genetics, 142: 1061-1064.

Nakashima A., Ishida H., Shigematsu M., Goto M., and Hanihara T. (2010) Nonmetric cranial variation of Jomon Japan: implications for the evolution of eastern Asian diversity. American Journal of Human Biology, 22: 782-790.

Nei M. (1995) The origins of human populations: genetic, linguistic, and archaeological data. In: Brenner S. and Hanihara K. (eds.), The Origin and Past of Modern Human as Viewed from DNA. World Scientific, Singapore, pp. 71-91.

Omono K. and Saitou N. (1997) Genetic origins of the Japanese: a partial support for the dual structure hypothesis. American Journal of Physical Anthropology, 102: 437-446.

Ossenberg N.S., Dodo Y., Maeda T., and Kawakubo Y. (2006) Ethnogenesis and craniofacial change in Japan from the perspective of nonmetric traits. Anthropological Science, 114: $99-115$.

Pääbo S., Poinar H., Serre D., Jaenicke-Després V., Hebler J., Rohland N., Kuch M., Krause J., Linda V., and Hofreiter M.
(2004) Genetic analysis from ancient DNA. Annual Review of Genetics, 38: 645-679.

R Development Core Team (2010) R: a language and environment for statistical computing. R Foundation for Statistical Computing, Vienna, Austria.

Rohland N. and Hofreiter M. (2007) Comparison and optimization of ancient DNA extraction. Bio Techniques, 42: 343-352.

Sato T., Amano T., Ono H., Ishida H., Kodera H., Matsumura H., Yoneda M., and Masuda R. (2009) Mitochondrial DNA haplogrouping of the Okhotsk people based on analysis of ancient DNA: an intermediate of gene flow from the continental Sakhalin people to the Ainu. Anthropological Science, 117: $171-180$.

Sato T., Kazuta H., Amano T., Ono H., Ishida H., Kodera H., Matsumura H., Yoneda M., Dodo Y., and Masuda R. (2010) Polymorphisms and allele frequencies of the ABO blood group gene among the Jomon, Epi-Jomon, and Okhotsk people in Hokkaido, northern Japan, reveraled by ancient DNA analysis. Journal of Human Genetics, 55: 691-696.

Schurr T.G., Sukernik R.I., Starikovskaya E.B., and Wallace D.C. (1999) Mitochondrial DNA variation in Koryaks and Itel'men: population replacement in the Okhotsk Sea-Bering Sea region during Neolithic. American Journal of Physical Anthropology, 108: 1-39.

Shinoda K. (2003) DNA analysis of the Jomon skeletal remains excavated from Shimo-Ohta shell midden, Chiba prefecture. Report for Sohnan Research Institute for Cultural Properties, 50: 201-205 (in Japanese).

Shinoda K. and Kanai S. (1999) Intracemetry genetic analysis at the Nakazuma Jomon site in Japan by mitochondrial DNA sequencing. Anthropological Science, 107: 129-140.

Starikovskaya E.B., Sukernik R.I., Schurr T.G., Kogelnik A., and Wallace D.C. (1998) Mitochondrial DNA diversity in Chukchi and Siberian Eskimos: implications for the genetic history of ancient Beringia and the peopling of the New World. American Journal of Human Genetics, 63: 1473-1491.

Starikovskaya E.B., Sukernik R.I., Derbeneva O.A., Volodko N.V., Ruiz-Pesini E., Torroni A., Brown M.D., Lott M.T., Hosseini S.H., Huoponen K., and Wallace D.C. (2005) Mitochondrial DNA diversity in indigenous populations of the southern extent of Siberia, and the origins of native American haplogroups. Annals of Human Genetics, 69: 67-89.

Tajima A., Hayami M., Tokunaga K., Juji T., Matsuo M., Marzuki S., Omoto K., and Horai S. (2004) Genetic origins of the Ainu inferred from combined DNA analyses of maternal and paternal lineages. Journal of Human Genetics, 49: 187-193.

Tanaka M., Cabrera V.M., González A.M., Larruga J.M., Takeyasu T., Fuku N., Guo L.J., Hirose R., Fujita Y., Kurata M., Shinoda K., Umetsu K., Yamada Y., Oshida Y., Sato Y., Hattori N., Mizuno Y., Arai Y., Hirose N., Ohta S., Ogawa O., Tanaka Y., Kawamori R., Shamoto-Nagai M., Maruyama W., Shimokawa H., Suzuki R., and Shimodaira H. (2004) Mitochondrial genome variation in eastern Asia and the peopling of Japan. Genome Research, 14: 1832-1850.

Trejaut J.A., Kivisild T., Loo J.H., Lee C.L., He C.L., Hsu C.J., Li Z.Y., and Lin M. (2005) Traces of archaic mitochondrial lineages persist in Austronesian-speaking Formosan populations. PLoS Biology, 3(8): e247.

Turner C.G., II (1987) Late Pleistocene and Holocene population history of East Asia based on dental variation. American Journal of Physical Anthropology, 73: 305-321.

Turner C.G., II (1990) Major features of sundadonty and sinodonty, including suggestions about East Asian microevolution, population history, and late Pleistocene relationships with Australian Aboriginals. American Journal of Physical Anthropology, 82: 295-317.

Umetsu K., Tanaka M., Yuasa I., Adachi N., Miyoshi A., Kashimura S., Park K.S., Wei Y.H., Watanabe G., and Osawa M. (2005) Multiplex amplified product-length polymorphism analysis of 36 mitochondrial single-nucleotide polymor- 
phisms for haplogrouping of East Asian populations. Electrophoresis, 26: 91-98.

van Oven M. and Kayser M. (2008) Updated comprehensive phylogenetic tree of global human mitochondrial DNA variation. Human Mutation, 30: E386-E394.

Weir B.S. and Cockerham C.C. (1984) Estimating F-statistics for the analysis of population structure. Evolution, 38: 13581370 .
Yamaguchi B. (1982) A review of the osteological characteristics of the Jomon population in prehistoric Japan. The Journal of the Anthropological Society of Nippon, 90 (Suppl.): 77-90.

Yao Y.G., Kong Q.P., Bandelt H.J., Kivisild T., and Zhang Y.P. (2002) Phylogeographic differentiation of mitochondrial DNA in Han Chinese. American Journal of Human Genetics, 70: 635-651. 


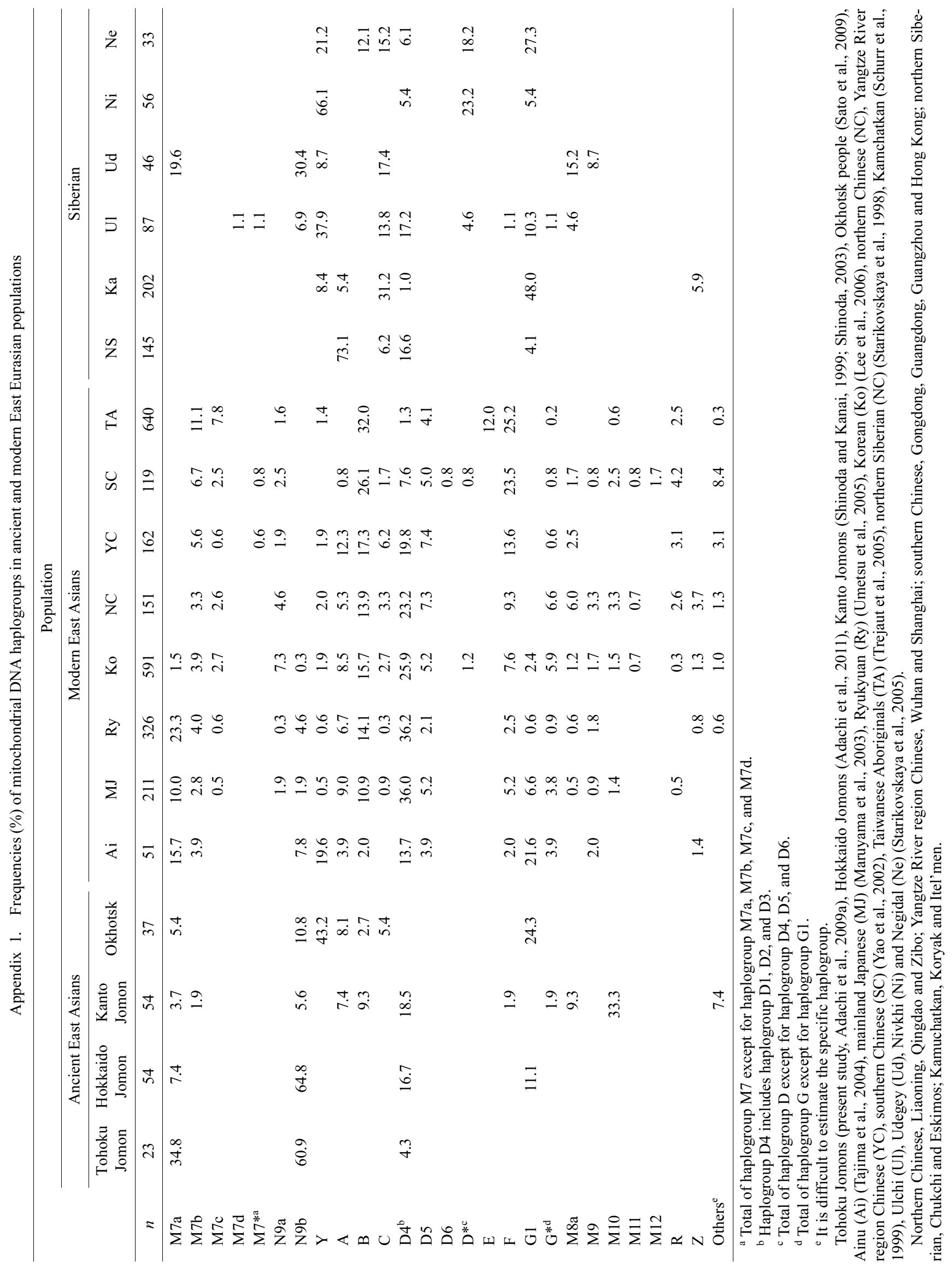




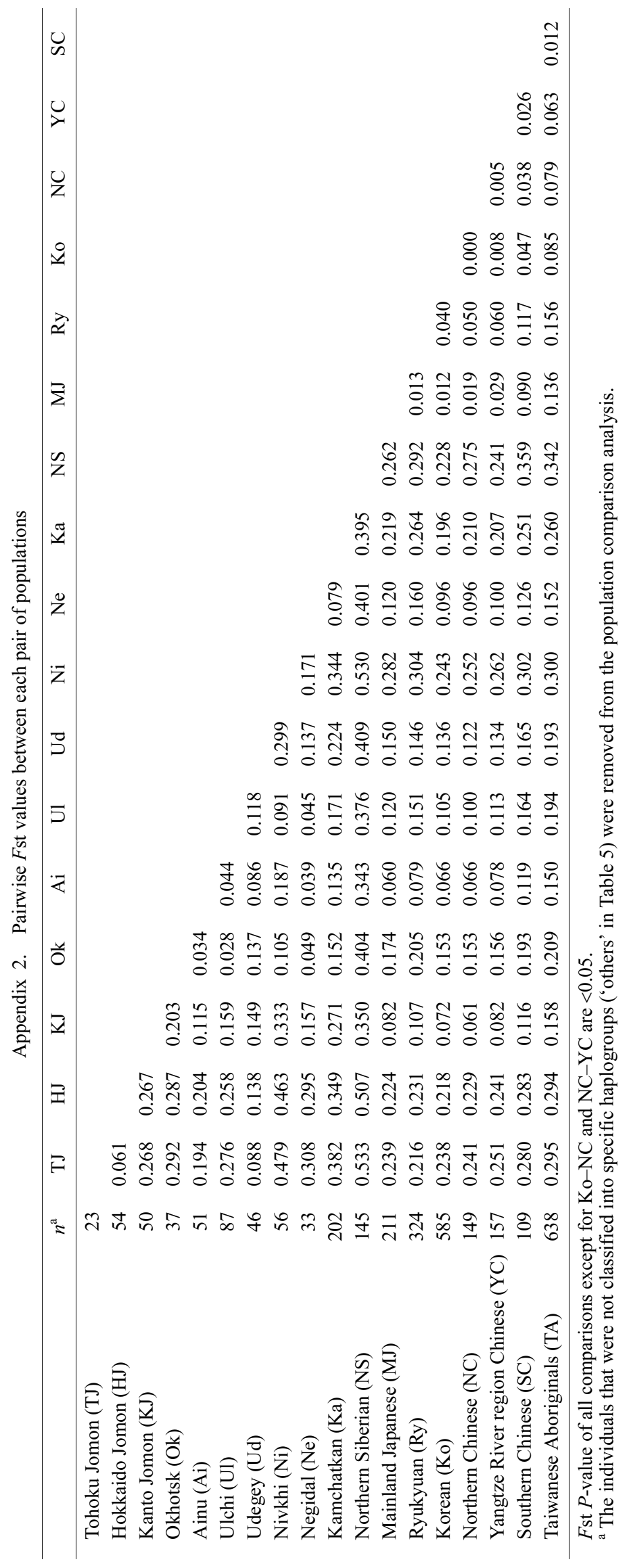

